\title{
Clinical Study of Acceptability And Safety of Postpartum Intrauterine Contraceptive Devices
}

\author{
Dr. Monika Yadav ${ }^{1}$,Dr. Kanti $\operatorname{Yadav}^{2}$,Dr. Sandhya Choudhary ${ }^{3}$,Dr. Ajay \\ Sharma \\ ${ }^{I}\left(3^{\text {rd }}\right.$ Year Resident Obstetrics And Gynecology, Rajkiya Mahila Chikitsalya, J.L.N. Medical College And \\ Hospital, Ajmer, India) \\ ${ }_{2}^{2}$ (Senior Professor And Head Of Department Obstetrics And Gynecology, Rajkiya Mahila Chikitsalya, J.L.N. \\ Medical College And Hospital, Ajmer, India) \\ ${ }_{3}^{3}$ (Assistant Professor Obstetrics And Gynecology, Rajkiya Mahila Chikitsalya, J.L.N. Medical College And \\ Hospital, Ajmer, India) \\ ${ }^{4}$ (Assistant Professor Obstetrics And Gynecology, Rajkiya Mahila Chikitsalya, J.L.N. Medical College And \\ Hospital, Ajmer, India)
}

\begin{abstract}
:
Objective: India is first to introduce family planning services, Government of India revised its policy in 2013 to permit trained nurses and midwives to insert postpartum intrauterine contraceptive devices (PPIUCDS). To assess the acceptability and safety of Postpartum Intrauterine Contraceptive Device insertion among women on bases of two key outcomes of PPIUCD insertions - expulsion and infection, who delivered at Rajkiya Mahila Chikitsalya J.L.N. Medical College and Hospital.

Method: this is a prospective interventional analytical study. The postpartum family planning services offered are in the form of health education in group counseling session at the postnatal ward.

Results: Total women counseled 1000, accepted 312, declined 688, lost to follow up 56, followed up 256, complications 82 (Expulsion 8, Bleeding 21, String problem 32, Removal 8, continuation 231)

Interpretation and conclusions: Immediate post-partum IUCD insertion provides highly effective contraception immediately after delivery. Although the expulsion rate for immediate post-partum is higher than for interval insertion particularly in country where women have limited access to medical care. The government needs to develop strategies to increase public awareness of the PPIUCD through different media sources. It is also important to arrange training on PPIUCD in order to increase knowledge and skills among health care providers. This will also further promote PPIUCD use and aid in reduction of expulsion rates. Case incentives to the acceptor, motivator and provider will bring about substantial progress in the PPIUCD use in developing countries like India.
\end{abstract}

Keywords: Complications, Expulsion, Intra caesarean insertion, Post-partum contraception, postpartum intrauterine contraceptive devices (PPIUCDs),

\section{Introduction}

Contraception methods by definition mean to prevent unwanted pregnancy by temporary or permanently [1]. India is second largest populated country in the world accounting for $17.5 \%$ of world's population by adding around 25 million births every year, $65 \%$ of women in the first year postpartum have an unmet need for family planning. [2,3]

Among the various method of family planning available for a women, insertion of post partum intrauterine contraceptive device appears appealing for several reasons: commencement of ovulation is unpredictable after delivery, women wish to avoid pregnancy, but still may not be using any form of contraception, delivery may be only time when a healthy woman comes in contact with health care providers[4], women is likely to be highly motivated for accepting contraception during post partum period, long term and reversible method, newer understanding about intrauterine contraceptive device in terms of acceptability ,low expulsion when inserted by proper technique ,cost effectiveness, safety and feasibility of inserting immediately after child birth[5], Keeping in mind all of the above, present study is undertaken.

The risk of expulsion can be reduced significantly by using proper technique of Postpartum Intrauterine Contraceptive Device insertion. There is no effect on breast milk quantity or quality.The above mentioned advantages argue a case for study in Postpartum Intrauterine Contraceptive Device with the aim of future inclusion of the method in the family planning programme. 


\section{Materials And Methods}

This is a prospective study was carried out in the department of Rajkiya Mahila Chikitsalya, Jawahar Lal Nehru Medical College Ajmer, Rajasthan from January 2014 to June 2015.Women delivering in the hospital fulfilling inclusion criteria was included in the study after obtaining informed consent.

2.1 Objectives of the present study are: to assess safety in terms of perforation, pain, bleeding, foul smelling vaginal discharge and assess expulsion rate at 6 weeks follow up and reasons for removal/discontinuation 2.2 Inclusion criteria: Women delivering vaginally or by caesarean section, counselled for IUD insertion in prenatal period or in labour and willing to participate in the study

2.3 Exclusion criteria: Anaemia (haemoglobin $<10 \mathrm{~g} / \mathrm{dl}$ ), $\mathrm{PPH}$, with premature rupture of membranes $>18$ hours, obstructed labour, fibroid, congenital malformation of uterus, active STD, lower genital tract infection and allergy to copper [6].

2.4 Counselling of the patients: Women were educated about family planning and using methods during ANC visits and at the time admission. Advantages of PPIUCD and complications were explained. Pretested questionnaire was filled to know acceptance and rejection, reasons to inclination to other methods were also recorded.

\subsection{Procedure Of Insertion Of PPIUCD}

2.5.1 Post placental: IUCD was inserted after 3rd stage labour management that is after placental removal. IUCD was inserted cautiously and aseptically into the uterine fundus.

2.5.2 Intra caesarean: IUCD was inserted directly into uterine fundus after delivery of placenta, then incision was closed.

2.6 Follow up: Follow up was done at 6 weaks in outpatient. Symptoms and signs of adverse effects due to IUCD insertion were noted like discharge, bleeding and pain abdomen. Inspected for threads, if threads were not found pelvic

\begin{tabular}{|c|c|c|c|c|c|c|}
\hline \multirow{2}{*}{ Characteristics $\mathrm{N}$} & \multirow{2}{*}{$\begin{array}{c}\text { Total counseled } \\
\mathrm{N}=1000\end{array}$} & \multicolumn{2}{|c|}{ Accepted } & \multicolumn{2}{|c|}{ Declined } & \\
\hline & & $\mathrm{N}=312$ & $\mathrm{~N}=(\%)$ & $\mathrm{N}=688$ & $\mathrm{~N}=(\%)$ & \\
\hline \multicolumn{6}{|l|}{ Age } & \\
\hline$<19$ & 64 & 3 & 0.96 & 61 & 8.86 & \multirow{3}{*}{$\begin{array}{c}p \text { value } \\
0.01\end{array}$} \\
\hline $20-29$ & 559 & 209 & 66.98 & 350 & 50.87 & \\
\hline $30-39$ & 369 & 96 & 30.76 & 273 & 39.68 & \\
\hline$>40$ & 8 & 4 & 1.28 & 4 & 0.58 & \\
\hline \multicolumn{6}{|l|}{ Education } & \\
\hline $\begin{array}{l}\text { No formal } \\
\text { education }\end{array}$ & 56 & 7 & 2.24 & 49 & 7.12 & \multirow{4}{*}{$\begin{array}{c}p \text { - value } \\
0.01\end{array}$} \\
\hline Primary & 311 & 146 & 46.79 & 165 & 23.98 & \\
\hline secondary & 577 & 134 & 42.94 & 443 & 64.38 & \\
\hline Higher education & 56 & 25 & 8.01 & 31 & 4.50 & \\
\hline \multicolumn{6}{|l|}{ Economic status } & \\
\hline Low & 547 & 152 & 48.71 & 395 & 57.41 & \multirow{3}{*}{$\begin{array}{c}p \text {-value } \\
0.035\end{array}$} \\
\hline Medium & 358 & 128 & 41.02 & 230 & 33.43 & \\
\hline High & 95 & 32 & 10.25 & 63 & 9.15 & \\
\hline \multicolumn{6}{|l|}{ Parity } & \\
\hline 1 & 572 & 189 & 60.57 & 383 & 55.67 & \multirow{3}{*}{$\begin{array}{c}p \text {-value } \\
0.12\end{array}$} \\
\hline 2 & 358 & 108 & 34.61 & 250 & 36.33 & \\
\hline$>3$ & 70 & 15 & 4.80 & 55 & 7.99 & \\
\hline \multicolumn{6}{|l|}{ Last child birth } & \multirow{5}{*}{$\begin{array}{c}p \text {-value } \\
0.01\end{array}$} \\
\hline $0-2$ & 508 & 177 & 56.73 & 331 & 48.11 & \\
\hline $2-3$ & 289 & 89 & 28.52 & 200 & 29.06 & \\
\hline $3-4$ & 172 & 32 & 10.25 & 140 & 20.34 & \\
\hline$>5$ Yrs & 31 & 14 & 4.48 & 17 & 2.47 & \\
\hline
\end{tabular}

ultrasound and x-ray pelvis was done. Women who came for follow up and want to remove IUCD, reasons were meticulously filled in the questionnaire

\section{Result}

Table I. Socio demographic and obstetric characteristics of the parturient included in the study $* \mathrm{p} \leq 0.05$ statistically significant

II. Reasons for acceptability among the parturient included in the study

\begin{tabular}{|l|c|c|}
\hline \multicolumn{1}{|c|}{ Reason for acceptability } & Number & Percentage \\
\hline Long term & 177 & 56.73 \\
\hline Safe & 61 & 19.55 \\
\hline Fewer clinic visit & 34 & 10.89 \\
\hline
\end{tabular}




\begin{tabular}{|l|c|c|}
\hline Reversible & 29 & 9.29 \\
\hline Non hormonal & 9 & 2.88 \\
\hline No interference with breast feeding & 2 & 0.64 \\
\hline
\end{tabular}

III. Reason for refusal among the parturient included in the study

\begin{tabular}{|l|c|c|}
\hline Reason for refusal & Number $(\mathrm{N}=688)$ & Percentage \\
\hline Prefer to use another method & 211 & 30.66 \\
\hline Satisfied with previous contraceptives & 118 & 17.15 \\
\hline Need to discuss with my partner & 102 & 14.82 \\
\hline Fear of pain and heavy bleeding & 98 & 14.24 \\
\hline Family/Partner refusal & 67 & 9.73 \\
\hline Don't want contraception immediately & 42 & 6.10 \\
\hline No reason & 21 & 3.05 \\
\hline Not enough knowledge about PPIUCD & 12 & 1.74 \\
\hline Fears cancer & 7 & 1.01 \\
\hline Interferes with sexual intercourse & 6 & 0.87 \\
\hline Religious beliefs & 4 & 0.58 \\
\hline
\end{tabular}

IV: Type of Postpartum Intrauterine Device insertion

\begin{tabular}{|l|c|c|}
\hline \multicolumn{1}{|c|}{ Type } & Number & Percentage \\
\hline $\begin{array}{l}\text { Post placental (within 10 minutes of delivery of placenta } \\
\text { after vaginal delivery }\end{array}$ & 199 & 63.78 \\
\hline $\begin{array}{l}\text { Immediate post-partum (10 minutes to 48 hours after child } \\
\text { birth) }\end{array}$ & 17 & 5.44 \\
\hline Intra caesarean & 96 & 30.76 \\
\hline
\end{tabular}

V. Complications at 6 weeks after Postpartum Intrauterine Contraceptive Device insertion ( $\mathrm{N}=82)$ :-

\begin{tabular}{|c|c|c|}
\hline Complications & Number $(\mathrm{N}=256)$ & Percentage \\
\hline Bleeding & 21 & 8.20 \\
\hline Menstrual disturbance & 6 & 2.34 \\
\hline Expulsion & 8 & 3.12 \\
\hline Strings not visible & 24 & 9.37 \\
\hline Pelvic Pain & 15 & 5.85 \\
\hline Pelvic infection & 7 & 2.73 \\
\hline Uterine perforation & 1 & 0.39 \\
\hline
\end{tabular}

VI. Reason For Discontinuation Of Intrauterine Contraceptive Device In The Study

\begin{tabular}{|l|c|c|}
\hline Reason & Number $(\mathrm{N}=25)$ & Percentage \\
\hline Expulsion & 8 & 3.12 \\
\hline Removal for & & \\
\hline Bleeding & 3 & 1.17 \\
\hline Menstrual disturbances & 1 & 0.39 \\
\hline Pelvic Pain & 2 & 0.78 \\
\hline Pelvic infection & 1 & 0.39 \\
\hline Uterine perforation & 1 & 0.39 \\
\hline Others including string problem & 2 & 0.78 \\
\hline Pressure from family & 7 & 2.73 \\
\hline
\end{tabular}

VII. Continuation rate (post placental 199+immediate post-partum 17+intracesarean 96) in the study:-

\begin{tabular}{|c|c|c|}
\hline Continuation rate & Number & Percentage \\
\hline Total insertion & 312 & \\
\hline Total follow up & 256 & 3.12 \\
\hline Expulsion & 8 & 6.64 \\
\hline Removal & 17 & 90.23 \\
\hline
\end{tabular}

VIII. Continuation rate in both groups of clients having and not having complications in the study:-

\begin{tabular}{|c|c|c|c|c|c|}
\hline Status & Number & $\begin{array}{c}\text { Removal } \\
\text { No. }\end{array}$ & $\%$ & $\begin{array}{c}\text { Continuatio } \\
\mathrm{n}\end{array}$ & $\%$ \\
\hline \multicolumn{6}{|c|}{ Having complications } \\
\hline Expulsion & 8 & & & & \\
\hline Bleeding & 21 & 3 & 14.28 & 18 & 78.26 \\
\hline Menstrual disturbances & 6 & 1 & 16.66 & 5 & 83.33 \\
\hline Pelvic Pain & 15 & 2 & 13.33 & 13 & 33.33 \\
\hline Pelvic infection & 7 & 1 & 14.28 & 6 & 85.71 \\
\hline
\end{tabular}




\begin{tabular}{|c|c|c|c|c|c|}
\hline Uterine perforation & 1 & 1 & 100 & 0 & 0 \\
\hline String Problem & 24 & 2 & 8.33 & 22 & 91.66 \\
\hline No Complications & 174 & 7 & 4.02 & 167 & 95.97 \\
\hline
\end{tabular}

\section{Conclusion}

Present study was conducted among 1000 parturient to assess their acceptability, feasibility and complications towards postpartum insertion of IUCD. After taking consent out of 1000, 312 women were accepted and 688 were declined. Socio-demographic features, obstetric characters and reasons for accepting the IUCD discussed here onwards.

Mean age of acceptance was $27.61 \pm 5.33$. Acceptance was more in those who completed their primary and secondary school level education $(89.73 \%)$. Majority of the women $(94.4 \%)$ had at least a primary level of education. Acceptance of the use of PPIUCD was higher among women with primary and higher education ( $46.95 \& 44.64 \%)$, than those with no formal education $(12.50 \%)$.

Anjali et al., found 36\% acceptance and and 64\% were declined for postpartum IUCD insertion [7]. Mishra S et al., found $17.17 \%$ of acceptance [8]. Gunjan goswamy et al., found $66.6 \%$ acceptance [9]. Vidyaramana et al., found $8.55 \%$ acceptance [10]. So much of variation in acceptance was found across country may be due to different study settings, locality and diversity in socio-demographic characteristics.

Anjali et al., and Misha S et al., found high acceptancy among women who completed their primary and secondary school education $[7,8]$. Gunjan goswamy et al., also found more acceptors who had completed secondary school education (49\%) followed by primary school (23\%), compared to illiterates (13\%) [9]. Vidyaramana et al., found more literacy will lead to acceptancy (15.7\%) compared to illiteracy (5.3\%) [10]. above all studies and current study reiterates that educational status has definitely high influence in acceptancy of PPIUCD.

Gunjan goswamy found lower income people were high acceptors (62\%) [9]. Satyavathi et al., found acceptance was high among low socioeconomic women had high acceptance (67\%) [11]. Current study also found similar results. It may be because study was conducted in government tertiary care hospital where majority service receivers are low socio economic people.

Anjali et al., Mishra S et al., Vidya ramana et al., and Satyavathi et al., found high acceptance among primi gravida women. [7, 8, 10,11]. Gunjan goswamy et al., found women with second gravida were high acceptors (48\%) [9]. Similar results to current study this is because IUCD is temporary method that is the reason for acceptancy among primi parous women.

Mishra S et al., and Satyavathi et al., found women who had at least one delivery were preferred temporary methods $[8,11]$.

Manju shukla et al., found $60.87 \%$ acceptors underwent cesarean section.[12]. Vidya ramana et al., found $83.73 \%$ of acceptors had cesarean section and $16.26 \%$ acceptors underwent vaginal delivery [10].but in our study $(69.22 \%)$ majority of acceptors underwent vaginal delivery than $(30.76 \%)$ intra caesarean.

Anjali et al., found $32 \%$ want another method of contraception, $18 \%$ had fear of complication, $8 \%$ not specified any reason to refusal of IUCD [7]. Priya et al., found husband was the main reason for not accepting IUCD [13]. Satyavathi et al., found in their study, majority were preferred another family planning method (46.68\%), followed by fear of complications (32.89\%) and due to family refusal (20.42\%) [11]. Reasons for refusal in Gunjan goswamy et al., study were fear of complications (41\%), not accepted by partner (35\%), 22\% were inclined to other methods, 5\% not had any reason and 1\% declined on religion basis (9) In our study, we found majority $(47.81 \%)$ were not accepting because they are interested in other methods followed by $(14.83 \%)$ had fear of complications and $9.73 \%$ were told partner was not interested. On religious base less than $1 \%$ were declined IUCD. Partner or family members are playing important role in the decision making. Educating family members may increase the acceptancy.

Anjali et al., found 28\% accepted because people it is long acting, 20\% accepted because IUCD needs few follow up visits, $17 \%$ because it is reversible, $10 \%$ accepted by stating that safe \& non hormonal and $11 \%$ accepted because attention needed to check [7]. study done by Satyavathi et al., found reasons for accepting IUCD were long acting (55.28\%), 20.73\% thought it is safe [11]. In our study, we found majority (56.73\%) accepted due to its long term effect $19.55 \%$ due its safety and $10.89 \%$ due to fewer clinic visits. Different views found in different study but majority studies stated that people accepting IUCD because it is long acting and safe.

Out of 312 accepted women 56 were lost to follow up after 6 weeks. Sixteen were reported complications. Main reported complications were bleeding (8.20\%), pain abdomen (5.85\%). Expulsion rate was $3.12 \%$.

In the present study, the expulsion rate was at $4-6$ wks interval were $8(3.12 \%)$. This was similar to a multicountry study done in Belgium, Chile and Phillippines which showed the rate of expulsion at 1 month ranging from 4.6 to $16 \%$.[14] which compares to the expulsion rate of 5.6\% reported among 210 women in a clinic in Hubli, Karnataka state in India [15], 1.6\% among 3000 women in a hospital in Paraguay [16], and 5.6\% 
among women among 305 periurban Lusaka, Zambia [17]. Another study of 1317 women in north India reported a cumulative expulsion rate of $10.7 \%$ by six months [12].

Anjali et al., observed $28 \%$ lost follow up. Majority (22\%) were expelled, $8 \%$ had pain abdomen and $6 \%$ found menstrual irregularities [7]. Mishra S et al., found expulsion rate $6.4 \%$ at 6 weeks. A $23.05 \%$ participants were lost follow up [8]. Gunjan goswamy et al., found expulsion rate was $10 \%$ and $30 \%$ lost follow up. In their study bleeding/discharge (30\%), abdominal pain $(20 \%)$, family pressure $(20 \%)$, just did not want to continue $(5 \%)$ were the reasons they found for removal of IUCD in the follow up [9]. Vidya ramana et al.,observed high follow up (93\%). Very minimal percentage expelled and went for removal due to complications like pain and discharge [10]. Satyavathi et al., found reasons for removal were bleeding (27.27\%), menstrual disturbances $(18.18 \%)$, pressure from family $(27.27 \%)$ other problems $(18.18 \%)$ and pain $(9 \%)$ [10]. Majority studies including current study observed pain and discharge were the main problems for removal of IUCD.

\section{Limitations}

1.1 This study was conducted in a tertiary centre therefore the findings may not adequately reflect the entire primary region.

1.2 Lost to follow up as observed in the study was a limitation of the study. This made it difficult to draw a clear conclusion as what happened to those who did not complete their follow up schedule.

1.3 The present study is limited in that long-term expulsion rates could not be determined since follow-up was only conducted at six weeks following birth. Further studies could be conducted that involved one or two year follow-up assessments.

\section{Conclusion}

This study of PPIUCD use showed that most women were satisfied with their choice of immediate insertion of an IUCD and that the rates of problems and complications were relatively low. We can conclude that Inserting CuT 380 A by 10 min after placental delivery is safe and effective, has high retention rate. The expulsion rate was not high, and further can be reduced with practice. With the high level of acceptance, despite low levels of awareness, the government needs to develop strategies to increase public awareness of the Postpartum Intrauterine Contraceptive Device through different media sources.

\section{Bibilography}

[1]. Park K. social and preventive medicine. 23 rd ed. Jabalpur: Banarsidas bhanot; 2015.

[2]. India at Glance - Population census 2011. Census organization of India, 2011.Available at: http://censusindia.gov.in/2011-provresults/indiaatglance. html. Accessed 21st July 2015.

[3]. Post-partum. IUCD reference manual. New Delhi: Family Planning Division, Ministry of Health and Family Welfare, Government of India; 2010.

[4]. Grimes D, Schulz K, Van Vliet H, Stanwood N. et al Immediate postpartum insertion of intrauterine devices (Cochrane Review). Cochrane Database Syst Rev 2003;(1):CD003036.

[5]. Sevki Celen, Perran Moroy et al Clinical outcomes of early postplacental insertion of intrauterine contraceptive devices, Contraception 69 (2004) 279-282.

[6]. Bluestone J, Chase R, Lu ER. USAID IUD guide lines for family planning services programme 3rd edition A Problem-Solving Reference Manual 2008

[7]. Kanhere A, Pateriya P, Jain M. Acceptability and Feasibility of Immediate post-partum IUCD insertion in a tertiary care centre in Central India. International Journal of Reproduction, Contraception, Obstetrics and Gynecology. [Internet]. $2015 ; 4(1): 1$.

[8]. Mishra S. Evaluation of Safety, Efficacy, and Expulsion of Post-Placental and Intra-Cesarean Insertion of Intrauterine Contraceptive Devices (PPIUCD). J Obstet Gynaecol India. 2014;64(5):337-43.

[9]. Gunjan Goswami, et al. A Prospective Study to Evaluate Safety, Efficacy and Expulsion Rate of Post Placental Insertion of Intra Uterine Device. Journal of Evolution of Medical and Dental Sciences. 2015;4(56):9770-74.

[10]. Vidyarama R, Nagamani T, Ppiucd K. Ppiucd As A Long Acting Reversible Contraceptive (Larc) - an Experience at A Tertiary care Centre. 2015. pp. 5-7.

[11]. Maluchuru S, Aruna V. Post Partum - Intrauterine Device Insertion - 2yr Experience at a Tertiary Care Center in Guntur Medical College /Govt. General Hospital, Guntur. IOSR Journal of Dental and Medical Sciences Ver IV [Internet]. 2015;14(7):2279-861.

[12]. Shukla M, Qureshi S, Chandrawati. Post-placental intrauterine device insertion - A five year experience at a tertiary care centre in North India. Indian Journal of Medical Research [Internet]. 2012;136(3): 432-35.

[13]. Jha P. Compendium of sessions addressing south Asian health at the 2012 APHA meeting. In: Priya Jha, eds. SAPHA Compendium. India: Compiled by the South Asian Public Health Association (SAPHA); 2012:8-72.

[14]. Agustin Conde-Agudelo, et al., "Birth Spacing and the Risk of Adverse Perinatal Outcomes: A Meta-Analysis," The Journal of the American Medical Association 29 (April 19, 2006): 1809-1923.

[15]. Kittur S, Kabadi YM: Enhancing contraceptive usage by post-placental intrauterine contraceptive devices (PPIUCD) insertion with evaluation of safety, efficacy, and expulsion. Int J Reprod Contracept Obstet Gynecol 2012,1:26-32.

[16]. Araujo VB, Ortiz L, Smith J: Postpartum IUD in Paraguay: a case series of 3000 cases. Contraception 2012, 86:173-186.

[17]. Blumenthal P, Shiliya N, Neukom J, Chilambwe J, Vwalika B, Prager B, Gupta P, Espey E, Eber M: Expulsion rates and satisfaction levels among immediate postpartum IUD users in peri-urban Lusaka, Zambia. Contraception 2011, 84:320. 